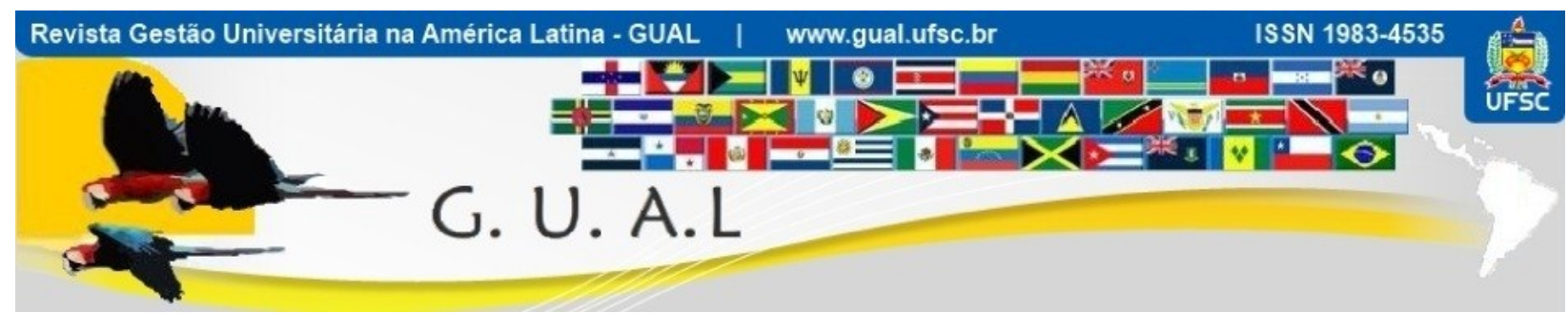

DOI: http://dx.doi.org/10.5007/1983-4535.2013v6n2p1

\title{
EDUCAÇÃO A DISTÂNCIA COMO POLÍTICA DE INCLUSÃO: UM ESTUDO EXPLORATÓRIO NOS POLOS DO SISTEMA UNIVERSIDADE ABERTA DO BRASIL EM MINAS GERAIS
}

\section{DISTANCE EDUCATION AS POLITICAL OF INCLUSION: AN EXPLORATORY STUDY IN POLES OF OPEN UNIVERSITY OF BRAZIL SYSTEM IN MINAS GERAIS}

Lilian Ferrugini, Mestre Universidade Federal de Lavras - UFLA lilianufjf@yahoo.com.br

Donizeti Leandro Souza, Mestre Universidade Federal de Lavras - UFLA souza.doni@yahoo.com.br

Marcio Siqueira, Doutor Pontifícia Universidade Católica de Minas Gerais - PUC-Minas marcio@comasi.com.br

Cleber Carvalho Castro, Doutor Universidade Federal de Lavras - UFLA clebercastrouai@gmail.com

Recebido em 05/fevereiro/2013

Aprovado em 03/abril/2013

Sistema de Avaliação: Double Blind Review 


\title{
RESUMO
}

O objetivo deste artigo é identificar os possíveis impactos que o acesso ao ensino superior pode gerar em municípios mineiros com baixos índices de desenvolvimento municipal, sendo o sistema UAB (Universidade Aberta do Brasil) uma importante política de inclusão, principalmente em municípios menores. Partindo de uma pesquisa exploratória - descritiva através de indicadores socioeconômicos relacionados à renda, escolaridade média e desenvolvimento municipal através do Índice Firjan de Desenvolvimento Municipal - IFDM (2012), em conjunto com um estudo de caso realizado no polo presencial de Santa Rita de Caldas/MG, foi possível identificar prováveis benefícios que a Educação a Distância, através do sistema UAB, pode gerar em municípios mineiros. Identificou-se ainda que a maioria dos polos presenciais do sistema UAB está presente em cidades com até 60 mil habitantes, demonstrando a presença e o potencial dessa modalidade de ensino como instrumento dinamizador de desenvolvimento regional, além de identificar fortes evidências entre os níveis de acesso à educação e desenvolvimento socioeconômico, estando os municípios com maiores índices de acesso ao ensino superior entre os municípios com maior distribuição de renda e desenvolvimento municipal.

Palavras-chave: Educação a distancia. Políticas de incluso. Desenvolvimento municipal.

\begin{abstract}
The aim of this paper is to identify the possible impacts that access to higher education can generate in Minas Gerais towns with low rates of municipal development, being the OUB system (Open University of Brazil) an important inclusion policy, especially in smaller towns. Starting from an exploratory research - descriptive, through socioeconomic indicators related to income, average education and city development by municipal development Index Firjan IFDM (2012), in conjunction to a case study carried out at the pole of Santa Rita de Caldas/MG, it was possible to identify probable benefits that distance education through the OUB system, can generate in Minas Gerais towns. It was also found that most of the poles of OUB system is present in cities with up to 60,000 inhabitants, demonstrating the presence and potential of this type of education as a tool to foster regional development, beyond identifying strong evidence between levels of education access and socioeconomic development, being the towns with the highest rates of access to higher education among the cities with higher income distribution and municipal development.
\end{abstract}

Keywords: Distance Education. Policies inclusion. Municipal development. 


\section{EDUCAÇÃO A DISTÂNCIA COMO POLÍTICA DE INCLUSÃO: UM ESTUDO EXPLORATÓRIO NOS \\ POLOS DO SISTEMA UNIVERSIDADE ABERTA DO BRASIL EM MINAS GERAIS \\ DOI: http://dx.doi.org/10.5007/1983-4535.2013v6n2p1}

\section{INTRODUÇÃO}

A Educação e o conhecimento sempre foram fatores indispensáveis para qualquer nação se desenvolver. Contudo, nas últimas décadas, educação e conhecimento tornaram os elementos diferenciadores no mundo capitalista competitivo. Depreende-se de estudos já realizados, que um país só alcança patamares de desenvolvimento e competitividade quando é capaz de proporcionar educação de qualidade à sua população. Nesse sentido, afirma-se que o crescimento e desenvolvimento de um país, seja na esfera econômica, política ou social, são proporcionalmente dependentes do nível educacional proporcionado à sua população (ALLEN \& SEAMAN, 2010).

Com o objetivo de proporcionar maior acesso à educação superior, autoridades brasileiras têm desenvolvido mecanismos, a partir de propostas que unem instituições em prol da melhoria do acesso à educação no país, como é o caso do sistema UAB (Universidade Aberta do Brasil), voltado para o crescimento da oferta pública de cursos superiores a distância, por meio da ampliação do número de vagas nas mais diversas regiões do país. Assim, a Educação a Distância tem sido um importante instrumento de viabilização do acesso à educação superior, pois amplia oportunidades a indivíduos e grupos que muitas vezes não possuem flexibilidade de tempo e recursos necessários para ingressarem em cursos presenciais (tradicionais).

Importante destacar que para o desenvolvimento eficiente das atividades pedagógicas inerentes aos cursos na modalidade de Educação a Distância (EaD), existem os polos de apoio presencial implantados em municípios, em sua maioria do interior, visando promover o acompanhamento necessário aos cursos ali ministrados. Assim, os polos constituem o espaço físico onde acontecem os momentos presenciais, sendo responsáveis pelo acompanhamento, orientação e interação de alunos na promoção e efetivação da EaD.

Neste sentido, o objetivo deste artigo é identificar os possíveis impactos que o acesso ao ensino superior pode gerar em municípios mineiros com baixos índices de desenvolvimento municipal, destacando a importância da democratização do acesso à educação superior e seu impacto direto na melhoria de renda e desenvolvimento local. Assim o estudo se justifica por despertar em gestores municipais a importância de desenvolver políticas públicas capazes de promover desenvolvimento socioeconômico municipal através de melhorias no acesso à educação superior, sendo o sistema UAB uma importante alternativa de inclusão desta modalidade de ensino, principalmente em municípios menores. 


\section{REFERENCIAL TEÓRICO}

\subsection{A importância da Educação para o desenvolvimento socioeconômico}

A educação sempre foi um importante fator de desenvolvimento. Na atualidade, percebe-se que a educação a distância assume um papel ainda mais importante no desenvolvimento econômico e social, tornando-se um fator de desenvolvimento da própria educação (MORAES, 2010).

Nos últimos anos, o conhecimento passou a assumir a categoria central de qualquer processo educacional, sendo o elemento diferenciador de um mundo capitalista marcado pela alta competitividade de mercados e processos de produção. Assim, o conhecimento tornou-se o elemento principal na produção de riqueza, explicitando-se com muita nitidez sua imediata vinculação com o universo do trabalho, sendo papel da educação promover uma justa “distribuição" desse "bem” (MACHADO, 2001).

Neste cenário, a educação como principal fonte de informação e geração de conhecimento, tornou-se uma unanimidade mundial como instrumento de desenvolvimento socioeconômico, pois através desta é possível promover o crescimento pessoal e social de indivíduos/grupos sociais mais carentes, além de reduzir desigualdades no mundo contemporâneo (BERTOLIN, 2011; ARIEIRA et al., 2009). A educação passa a ser "um elemento de dinamicidade na sociedade, a forma mais rápida de um país diminuir suas desigualdades sociais internas e a distância econômica e tecnológica que o separa dos países mais ricos e desenvolvidos mundialmente" (ARIEIRA et al., 2009, p. 318).

É possível notar que os países bem posicionados na chamada Nova Economia estão baseados intensivamente no conhecimento, sendo estes os que proporcionam maior acesso à educação e onde esta atividade é desenvolvida de maneira mais qualificada (MORAES, 2010). Nesse sentido, a educação superior assume uma posição central neste cenário, pois representa o instrumento transformador indispensável para o alcance de novos patamares de crescimento e desenvolvimento (BERTOLIN, 2011; NASCIMENTO \& TROMPIERI FILHO, 2002).

Percebe-se assim, que a importância da educação na sociedade tem despertado a atenção de políticas públicas educacionais com vistas à expansão e democratização do acesso a educação superior no país, além de promover melhorias no desempenho brasileiro em indicadores internacionais como: Índice de Desenvolvimento Humano (IDH), Índice de GINI (Instrumento para medir a desigualdade na concentração de renda), Programme for 
International Student Assessment (PISA), Produto Interno Bruto percapta (PIB percapta), Taxas de atendimento da educação, dentre outros (BERTOLIN, 2011). Esses índices quando comparados com os de países desenvolvidos demonstram a ineficiência do setor educacional no Brasil, gerando reflexões preocupantes, pois o crescimento e desenvolvimento de um país, seja na esfera econômica ou social, é demasiadamente dependente do nível educacional da população (ALLEN \& SEAMAN, 2010).

Tabela 1 Comparação de indicadores entre Brasil e países desenvolvidos

\begin{tabular}{lcccc}
\hline \multicolumn{1}{c}{ Países } & PIB percapta (2010) & IDH (2011) $^{\mathbf{1}}$ & GINI $^{\mathbf{2}}$ & PISA (2009) $^{\mathbf{3}}$ \\
\hline EUA & 46.546 US\$ & 0,910 & $0,463(2007)$ & 496 \\
Japão & 43.141 US\$ & 0,901 & $0,376(2008)$ & 529 \\
Alemanha & 39.857 US\$ & 0,905 & $0,270(2006)$ & 510 \\
França & 39.546 US\$ & 0,884 & $0,327(2008)$ & 497 \\
Reino Unido & 36.327 US\$ & 0,863 & $0,410(2008)$ & 500 \\
Brasil & 10.716 US\$ & 0,718 & $0,519(2012)$ & 401 \\
\hline
\end{tabular}

Fonte: Elaborado pelos autores

Neste contexto, percebe-se que nos últimos anos a Educação a Distância tem sido um importante instrumento de inclusão, pois não apenas amplia oportunidades para indivíduos e grupos sociais mais carentes, parece haver claras evidências empíricas que ela amplia o poder de fogo de acesso à educação, em geral, como fator de desenvolvimento (MORAES, 2010).

\subsection{Educação a Distância no cenário brasileiro}

A Educação a Distância disposta pelo Decreto 5.622/05 é caracterizada como a modalidade educacional na qual "a mediação didático-pedagógica nos processos de ensino e aprendizagem ocorre com a utilização de meios e tecnologias de informação e comunicação, com estudantes e professores desenvolvendo atividades educativas em lugares ou tempos diversos" (Art.1). É um modelo inovador que utiliza as Tecnologias da Informação e Comunicação (TIC's) para facilitar o aprendizado sem as limitações de tempo ou de lugar evidenciados na modalidade de ensino presencial (MAIA \& MEIRELLES, 2002), no qual tende a organizar-se segundo metodologia, gestão e sistemas de avaliação com características próprias (Decreto 5.622/05).

\footnotetext{
${ }^{1}$ Fonte: http://www.ibge.gov.br/paisesat/, acesso em 31/01/2013.

${ }^{2}$ Fonte: https://www.cia.gov/library/publications/the-world-factbook/fields/2172.html, acesso em 31/01/2013.

${ }^{3}$ Fonte: http://www.oecd.org/pisa/46643496.pdf, acesso em 31/01/2013.
} 


\section{EDUCAÇÃO A DISTÂNCIA COMO POLÍTICA DE INCLUSÃO: UM ESTUDO EXPLORATÓRIO NOS \\ POLOS DO SISTEMA UNIVERSIDADE ABERTA DO BRASIL EM MINAS GERAIS \\ DOI: http://dx.doi.org/10.5007/1983-4535.2013v6n2p1}

Na visão de Nascimento \& Trompieri Filho (2002), a Educação a Distância é uma modalidade de ensino na qual, educadores e educandos, não precisam estar juntos fisicamente para que o processo de aprendizagem seja construído. Eles podem estar interligados por meio de tecnologias síncronas ou assíncronas, na medida em que estas ferramentas tecnológicas ou TIC's, possibilitam a redução de distâncias ao mesmo tempo em que dão margem à difusão de informações e novos conhecimentos (NOGUEIRA, 1996).

Alonso (2010); Moreira \& Kramer (2007) atentam que a modalidade de ensino a distância, caracterizada por esta não presencialidade, apresenta algumas particularidades importantes, pois o controle do aprendizado passa a estar mais ligado ao próprio aluno. Identifica-se nesse sentido, a necessidade de meios tecnológicos interativos e de práticas pedagógicas específicas na viabilização de processos comunicacionais eficazes para reinventar o processo de ensinar e aprender, o que se dinamiza a partir da intenção e interação do próprio aluno como o processo de aprendizado.

Estudos de Arbaugh \& Benbunam-Fich (2006) demonstram que o conhecimento é facilitado a partir da interação dos indivíduos, ou seja, grupos de estudos são fundamentais para o aprendizado, permitindo que alunos reflitam e contribuam uns com ou outros na elaboração de seus pensamentos antes de expressá-los. Assim, a difusão do conhecimento é facilmente desenvolvida a partir da combinação de grupos de pessoas que estão mais aptas e capazes de produzir níveis consideráveis de aprendizagem, pois a dimensão social é essencial e de fundamental importância para o sucesso da modalidade de ensino a distância (REDPATH, 2012). Conclui-se que a interação entre os indivíduos é peça-chave para o desenvolvimento educacional nesta modalidade de ensino.

Já Mohamed, Hassan e Spencer (2011) advogam sobre a importância que a Educação a Distância representa para determinados grupos sociais, os quais não precisam abandonar emprego ou família para aprimorar seus conhecimentos e, consequentemente, melhorar sua capacitação profissional. Corroborando com estes conceitos, Parietti \& Turi (2011) relatam que tanto professores quanto alunos ingressantes em cursos a distância avaliam a modalidade positivamente, pois o mesmo proporciona flexibilidade e gerenciamento do tempo de estudo, o que facilita o acesso e a democratização de oportunidades a grupos mais carentes.

No Brasil, percebe-se que a Educação a Distância teve um aumento expressivo a partir de 2005, principalmente através do ensino superior que assumiu uma significativa expansão no número de matrículas entre o período de 2005 a 2009, com ritmo ligeiramente inferior em 
2010, ano em que $14,6 \%$ do total de matrículas no país correspondiam à modalidade EaD (930.179 matrículas), das quais $80,5 \%$ representavam as vagas do setor privado e $19,5 \%$ do setor público, conforme apresentado pelo Censo da Educação Superior de 2010 no gráfico 1.

Este cenário demonstra que a Educação a Distância tem assumido um modelo de ensino em expansão no país que se constitui em uma oportunidade de aprendizado capaz de trazer impactos positivos para uma sociedade por meio do acesso ao mundo do conhecimento (Gatti, 2008; Matias-Pereira, 2008; Segenreich, 2003; Arieira et al., 2009).

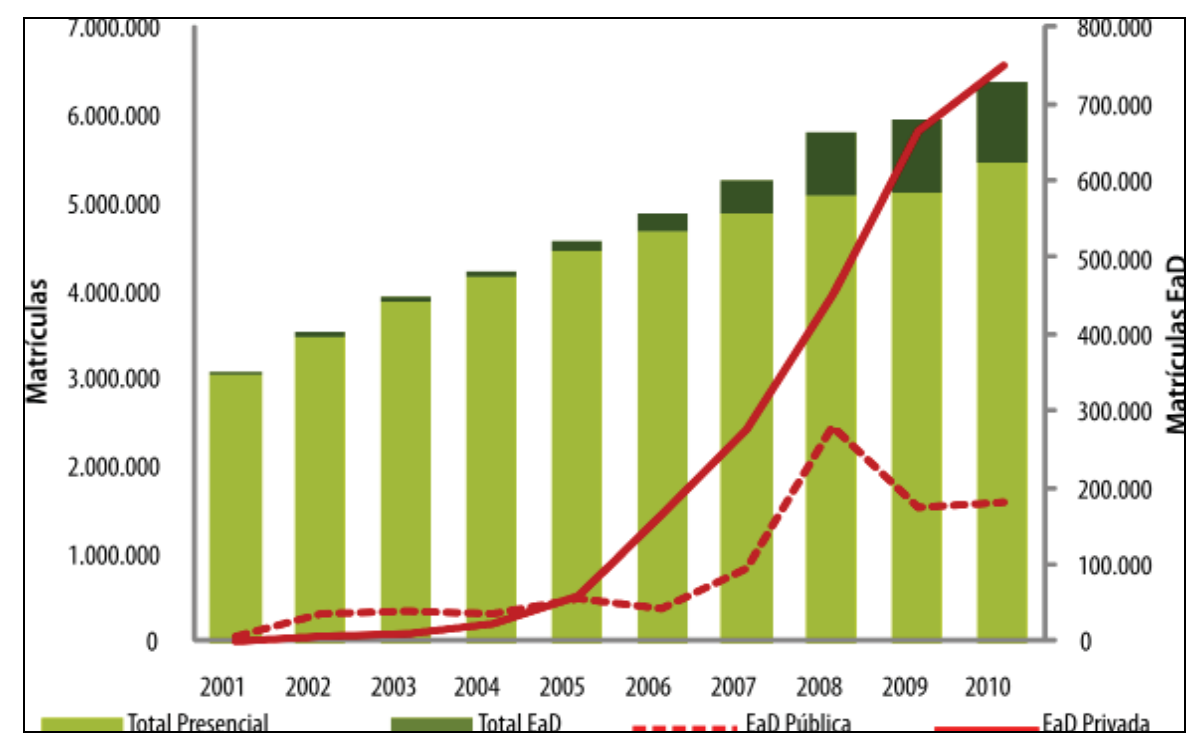

Gráfico 1 Evolução do número de matrículas de graduação por modalidade de ensino e número de matrículas a distância Públicas/Privadas no Brasil: 2001 - 2010 Fonte: MEC/INEP (2012, p. 42).

Ao contribuir com o processo de democratização da educação, proporcionando conhecimento para públicos e locais não contemplados pelo ensino superior tradicional (presencial), a EaD torna-se um pilar para o processo de institucionalização da educação, abrangendo locais e pessoas inimagináveis até então (Costa, 2012; PEREIRA, 2008). Tal fato tem se tornado abrangente a partir do sistema UAB, o qual tem se refletido como um importante elemento da política educacional no Brasil, conforme apresentado a seguir.

\subsection{O Sistema Universidade Aberta do Brasil (UAB)}

A regulamentação do sistema UAB realizado no ano de 2005 tem contribuído para a expansão da Educação a Distância no país. Trata-se de uma política pública instituída a partir da articulação entre a Secretaria de Educação a Distância do Ministério da Educação (SEED/MEC) e a Diretoria de Educação a Distância da Coordenação de Aperfeiçoamento de 


\section{EDUCAÇÃO A DISTÂNCIA COMO POLÍTICA DE INCLUSÃO: UM ESTUDO EXPLORATÓRIO NOS \\ POLOS DO SISTEMA UNIVERSIDADE ABERTA DO BRASIL EM MINAS GERAIS \\ DOI: http://dx.doi.org/10.5007/1983-4535.2013v6n2p1}

Pessoal de Nível Superior (DED/CAPES), a qual buscou desenvolver a modalidade EaD para expandir a educação superior no país (Segenreich, 2009; UAB/CAPES).

Segundo UAB/CAPES, a Universidade Aberta do Brasil é um sistema integrado por universidades públicas que oferecem cursos de nível superior para camadas da população que têm dificuldade de acesso à formação universitária por meio do uso da metodologia da Educação a Distância. Um dos objetivos do sistema UAB caracteriza-se por atender demandas locais na preparação e capacitação de indivíduos, em especial, nas regiões mais carentes da sociedade, democratizando o acesso à educação superior, para atuarem no mercado de trabalho de forma mais justa e competitiva (Moré et al., 2011).

Instituído pelo Decreto 5.800/06, esta política pública de acesso a educação surgiu diante da necessidade de expandir e interiorizar a oferta de programas de educação superior no país, centrados em diretrizes estratégicas da política nacional de educação através dos seguintes objetivos; (I) oferecer, prioritariamente, cursos de licenciatura e de formação inicial e continuada de professores da educação básica; (II) oferecer cursos superiores para capacitação de dirigentes, gestores e trabalhadores em educação básica dos Estados, do Distrito Federal e dos Municípios; (III) oferecer cursos superiores nas diferentes áreas do conhecimento; (IV) ampliar o acesso à educação superior pública; (V) reduzir as desigualdades de oferta de ensino superior entre as diferentes regiões do País; (VI) estabelecer amplo sistema nacional de educação superior a distância; e (VII) fomentar o desenvolvimento institucional para a modalidade de educação a distância, bem como a pesquisa em metodologias inovadoras de ensino superior apoiadas em tecnologias de informação e comunicação (Decreto 5.800/06, art. $1^{\circ}$ ).

Tendo como propósito central ampliar e democratizar o acesso à educação no país, o sistema UAB funciona como um instrumento eficaz de qualificação e requalificação de professores da educação básica e demais interessados com a universalização do acesso a uma educação pública de qualidade. Esta modalidade surge como alternativa capaz de incentivar o desenvolvimento de municípios com baixos IDH e IDEB (Índice de Desenvolvimento da Educação Básica) e, nesse aspecto, fortalecer a escola no interior do Brasil, minimizando a concentração de oferta de cursos de graduação nos grandes centros urbanos e, consequentemente, evitando o fluxo migratório para as grandes cidades (UAB/CAPES).

Desta forma, o sistema UAB sustenta-se em cinco eixos fundamentais: (1) expansão pública da educação superior; (2) aperfeiçoamento dos processos de gestão das instituições de 
ensino superior; (3) avaliação da educação superior a distância; (4) estímulo à investigação em educação superior a distância no País e; (5) financiamento dos processos de implantação, execução e formação de recursos humanos em educação superior a distância (UAB/CAPES).

Ressalta-se ainda, que o sistema UAB funciona como articulador entre as instituições de ensino superior e os governos estaduais e municipais, com vistas a atender as demandas locais por educação superior. Segundo Litto \& Formiga (2009) o sistema UAB não é uma universidade propriamente dita, mas sim um consórcio de instituições públicas de ensino superior responsável por fomentar ações necessárias ao funcionamento da modalidade de educação a distância, seja na produção e distribuição de material didático impresso, aquisição de livros e laboratórios pedagógicos, utilização de TIC's, integração entre tutores e estudantes, capacitação dos profissionais envolvidos, infraestrutura dos núcleos de educação e acompanhamento dos polos de apoio presencial implantados em municípios diversos.

Por fim, segundo dados da UAB/CAPES, existem atualmente 95 instituições públicas (federais e estaduais) credenciadas a ofertarem cursos em diversas modalidades de ensino pelo sistema UAB no país, abrangendo um total de 1029 cursos ofertados na modalidade EaD. Complementar a estas informações, a Portaria $n^{\circ}$ 1.369/10 estabelece um universo de 647 polos de apoio presencial credenciados pelo sistema UAB, espalhados pelas diversas regiões do Brasil, aos quais serão comentados na próxima seção.

\subsection{Polos de Apoio Presencial}

Consideram-se polos de apoio presencial, as unidades operacionais necessárias para o desenvolvimento descentralizado de atividades pedagógicas e administrativas relativas aos cursos e programas ofertados a distância pelo Sistema UAB. Os polos de apoio presencial podem ser entendidos como o "local de encontro" onde acontecem os momentos presenciais, necessários para o acompanhamento e a orientação para os estudos, as práticas laboratoriais e as avaliações presenciais, conforme legislação vigente (Decreto 6.303/07; UAB/CAPES).

Segundo Weidle et al. (2011), os polos presenciais são essenciais e indispensáveis para promover o desenvolvimento e o acompanhamento necessário aos cursos a distância, visto que os mesmos constituem o local onde permitirá interação presencial entre alunos e mediadores (tutores e professores) das disciplinas aplicadas. Assumem, assim, a "ponta" mais evidente da $\mathrm{EaD}$, responsável em grande parte pela concretização da qualidade do ensino prestado por esta modalidade (ALONSO, 2010). 


\section{EDUCAÇÃO A DISTÂNCIA COMO POLÍTICA DE INCLUSÃO: UM ESTUDO EXPLORATÓRIO NOS \\ POLOS DO SISTEMA UNIVERSIDADE ABERTA DO BRASIL EM MINAS GERAIS \\ DOI: http://dx.doi.org/10.5007/1983-4535.2013v6n2p1}

Mantidos por municípios ou governos de estado, os polos presenciais do Sistema UAB tem como objetivo oferecer a infraestrutura física, tecnológica e pedagógica necessária para que os alunos possam acompanhar os processos de aprendizagem, através de espaços físicos, bibliotecas, laboratórios de informática, serviços de comunicação e manutenção, incluindo acesso a internet, coordenação local, dentre outras exigências do MEC (UAB/CAPES; Decreto 5.800/06; ALONSO, 2010).

Devido a importância dos polos presenciais na qualidade de cursos EaD, há uma preocupação do MEC quanto a espaços físicos, mobiliários, recursos humanos e recursos de informática, visando manter o mínimo de estrutura e equidade entre os polos, possibilitando aos alunos os recursos básicos para o desenvolvimento e articulação do ensino e aprendizagem (WEIDLE et al. 2011).

Assim, a articulação entre os polos, Instituições de Ensino e o sistema UAB é realizada mediante edital publicado pelo Ministério da Educação, definindo os requisitos, condições e critérios de seleção dos mesmos, onde a candidatura de municípios interessados em ofertar cursos através da modalidade UAB independe das Instituições de Ensino Superior participantes, bastando atender os pré-requisitos solicitados pelo Ministério da Educação (Decreto 5.800/06; ALONSO, 2010).

Em Minas Gerais, foco deste estudo, somente no ano de 2010 foram ofertadas pelos polos presenciais 27.509 vagas, sendo 3.409 vagas $(12,4 \%)$ pela rede pública federal e 24.100 vagas $(87,6 \%)$ ofertadas pela rede privada de ensino (MEC/INEP, 2012). Nota-se, por estes dados, que apesar das políticas públicas de expansão da Educação a Distância pelo sistema $\mathrm{UAB}$, o acesso a EaD pública ainda é limitado frente a demanda cada vez maior por esta modalidade de ensino.

Desta forma, conhecer mais sobre os benefícios socioeconômicos que a Educação a Distância pode oferecer a municípios mineiros, assim como identificar as características de cada região com polos presenciais em funcionamento pelo sistema $U A B$, pode ser útil para impulsionar gestores de outras regiões do Estado a conhecerem e engajarem neste sistema de ensino como parte de uma política pública de acesso à educação e importante meio de promoção de desenvolvimento econômico e social do município. 


\section{EDUCAÇÃO A DISTÂNCIA COMO POLÍTICA DE INCLUSÃO: UM ESTUDO EXPLORATÓRIO NOS \\ POLOS DO SISTEMA UNIVERSIDADE ABERTA DO BRASIL EM MINAS GERAIS \\ DOI: http://dx.doi.org/10.5007/1983-4535.2013v6n2p1}

\section{PROCEDIMENTOS METODOLÓGICOS}

Após a realização de uma breve pesquisa bibliográfica buscou-se ampliar a percepção sobre a importância da EaD, em especial do Sistema UAB, como política pública de inclusão socioeconômica, surgindo como etapa complementar a definição de caminhos metodológicos utilizados neste estudo, assim como os critérios e métodos de pesquisa utilizados para um delineamento mais aprofundado dos conceitos apresentados.

Trata-se de um estudo exploratório-descritivo de caráter qualitativo e quantitativo, com vistas a conhecer com maior profundidade as características dos municípios mineiros com polos presenciais $\mathrm{UAB}$, identificando possíveis relações entre educação e indicadores socioeconômicos que fundamentem a importância de polos presencias pelo sistema UAB.

O procedimento de coleta de dados se deu, num primeiro momento, através de uma pesquisa documental de caráter quantitativo, que segundo Appolinário (2009) consiste numa estratégia de pesquisa utilizando-se apenas de fontes documentais como revistas, documentos legais, banco de dados eletrônicos, dentre outros, caracterizados pela busca de informações em documentos que não receberam tratamento científico, sem a utilização de fenômenos empíricos (OLIVEIRA, 2007).

Num segundo momento foi realizado um estudo de caso que, segundo GIL (2002), consiste num estudo aprofundado de uma temática, de maneira que permita seu amplo e detalhado conhecimento. A técnica utilizada foi a entrevista em profundidade com gestores responsáveis pela implantação e coordenação de um polo presencial através de roteiro semiestruturado para um aprofundamento do assunto abordado.

Posteriormente buscou-se triangular os dados qualitativos gerados pelo estudo de caso com dados quantitativos obtidos por meio da pesquisa documental em fontes como IBGE (Instituto Brasileiro de Geografia e Estatística), UAB/CAPES, INEP (Instituto Nacional de Estudos e Pesquisas Educacionais Anísio Teixeira), FIRJAN (Federação das Indústrias do Estado do Rio de Janeiro), cujos propósitos são abordar as seguintes variáveis:

(1) Distribuição geográfica de polos presenciais pelo sistema UAB em Minas Gerais;

(2) Características comuns e "perfil" médio dos municípios mineiros participantes do sistema UAB com polos presenciais em funcionamento, em relação à população, renda, indicadores sociais e acesso a educação superior;

(3) Relações entre acesso a educação e desenvolvimento socioeconômico nos municípios mineiros com polos $\mathrm{UAB}$ de até 60.000 habitantes; 


\section{EDUCAÇÃO A DISTÂNCIA COMO POLÍTICA DE INCLUSÃO: UM ESTUDO EXPLORATÓRIO NOS \\ POLOS DO SISTEMA UNIVERSIDADE ABERTA DO BRASIL EM MINAS GERAIS \\ DOI: http://dx.doi.org/10.5007/1983-4535.2013v6n2p1}

(4) Características de um polo presencial UAB e a relação com o desenvolvimento socioeconômico gerado sob a perspectiva dos gestores responsáveis.

Para a primeira variável da pesquisa: “distribuição geográfica de polos presenciais pelo sistema UAB em Minas Gerais", foi utilizado o banco de dados do portal UAB/Capes ${ }^{4}$ através do mecanismo de busca por polos presenciais, selecionando todos os municípios do estado de Minas Gerais.

O objetivo de análise desta variável foi identificar as regiões mineiras com polos presenciais, identificando o quão dispersos se encontram no Estado, e se está havendo de fato democratização de acesso via sistema UAB. Como etapa complementar ao estudo, foram analisados documentos como: o catálogo do sistema UAB (região sudeste), além de portarias de credenciamentos de polos presenciais pela modalidade UAB, cuja finalidade é explorar informações mais abrangentes ao mapeamento proposto.

Para a análise da segunda variável: "características comuns e "perfil" médio dos municípios participantes do sistema UAB com polos presenciais em funcionamento, em relação à população, renda, indicadores sociais e acesso a educação superior"; foi realizada uma pesquisa exploratória - descritiva em relatórios e banco de dados de órgãos como IBGE, INEP e FIRJAN. No banco de dados do IBGE a análise exploratória se deu através do censo 2010 e da base IBGE cidades@, com o propósito de identificar a população, renda média per capta nominal dos domicílios e taxa percentual da população economicamente ativa com curso superior em municípios mineiros com polos UAB referente ao censo de 2010.

Complementar às informações do IBGE foi realizado no portal MEC/INEP um mapeamento do ensino superior em Minas Gerais, além de uma pesquisa exploratória na base de dados da FIRJAN, por meio de indicadores socioeconômicos através do IFDM-2012 (Índice Firjan de Desenvolvimento Municipal) que avalia o desenvolvimento de todos os municípios brasileiros em três áreas: Emprego \& Renda, Educação e Saúde, com base em estatísticas públicas oficiais, disponibilizadas pelos Ministérios do Trabalho, Educação e Saúde através do ano base de 2010.

A justificativa da escolha deste indicador deve-se ao fato de sua metodologia permitir estabelecer relações entre os indicadores de um determinado município e a adoção de políticas específicas, aqui analisadas através de políticas educacionais (acesso), avaliando possíveis vantagens e impactos que a educação pode favorecer no desenvolvimento local. Trata-se de

\footnotetext{
${ }^{4}$ Fonte: $<$ http://www.uab.capes.gov.br/> acesso em 31/01/2013.
} 
um indicador similar ao IDH-M (Índice de Desenvolvimento Humano Municipal), com a diferença de ser o IFDM mais atualizado (dados referentes ao ano de 2010, publicados em 2012), ao invés do IDH-M que possui, até a data da pesquisa, dados relacionados ao ano base de 2000, publicados em 2003), demonstrando com maior confiabilidade o perfil dos municípios em estudo, principalmente após a implantação do sistema UAB.

Para a análise da terceira variável: "relações entre acesso a educação $e$ desenvolvimento socioeconômico nos municipios mineiros com polos UAB de até 60.000 habitantes" foi realizado um cruzamento de dados coletados nos bancos de dados da UAB/CAPES, IBGE, INEP e FIRJAN com o propósito de avaliar e descrever os principais aspectos que o acesso a educação pode favorecer no desenvolvimento regional, tendo como base dados populacionais, renda, acesso a educação superior e indicadores IFDM-2012.

Por fim, para a análise da última variável “Características de um polo presencial UAB e a relação com o desenvolvimento socioeconômico sob a perspectiva dos gestores responsáveis", foi realizado um estudo de caso no polo de Santa Rita de Caldas por motivos de conveniência e, por este representar um polo referência na região do Sul de Minas em relação a acesso a educação, o que muito aproxima do perfil abordado neste estudo.

\section{RESULTADOS E DISCUSSÃO}

\subsection{Características dos municípios, cursos e acesso a educação via sistema UAB:}

Em relação ao mapeamento proposto para os municípios participantes do sistema $\mathrm{UAB}$, foi identificado, por meio de pesquisas exploratórias realizadas no portal UAB/CAPES e análise documental em portarias de credenciamento dos polos, um universo de 88 polos de apoio presencial credenciados até o ano de 2010 (Portaria 1.369/10), distribuídos em todas as regiões do Estado. Para um Estado com 853 municípios catalogados pelo IBGE, o número de municípios que contemplam polos UAB é de apenas $10,3 \%$ do total, considerando todos os polos credenciados.

Levando em consideração apenas os polos em funcionamento, segundo portal da $\mathrm{UAB}$, este número cairia para 69 municípios, representando um percentual de apenas $8,1 \%$ de cidades mineiras ofertantes de cursos na modalidade UAB, conforme apresentado na figura 1: 


\section{EDUCAÇÃO A DISTÂNCIA COMO POLÍTICA DE INCLUSÃO: UM ESTUDO EXPLORATÓRIO NOS \\ POLOS DO SISTEMA UNIVERSIDADE ABERTA DO BRASIL EM MINAS GERAIS \\ DOI: http://dx.doi.org/10.5007/1983-4535.2013v6n2p1}

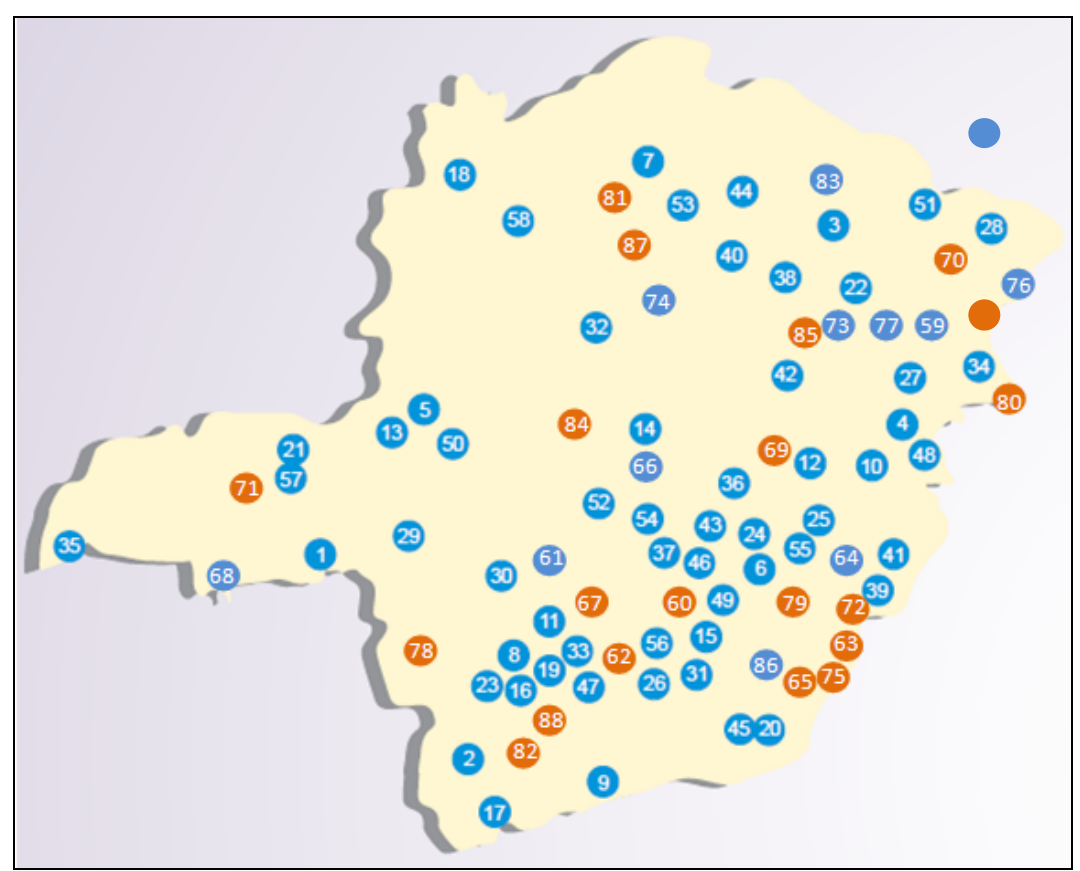

Legenda:

Polos credenciados com oferta de cursos pelo sistema UAB

Polos credenciados, em fase de implantação ou sem ofertas de cursos pelo sistema UAB

Figura 1 Distribuição geográfica dos municípios mineiros com polo UAB Fonte: Adaptado do Catálogo UAB/CAPES

Tal fato demonstra que, apesar da evidente dispersão geográfica descrita no mapa acima, a EaD ainda dispõe de vasto campo para ampliação no Estado, visto haver crescente aumento da demanda por esta modalidade de ensino nos últimos anos (MEC/INEP, 2012) em relação a quantidade ofertada pelos municípios mineiros atendidos pelo sistema UAB.

Já em relação às instituições de ensino participantes do sistema $U A B$, foram identificadas 14 instituições de ensino ofertantes de cursos em Minas Gerais, com destaque a Universidade Federal de Minas Gerais, Universidade Federal de Juiz de Fora, Universidade Estadual de Montes Claros e Universidade Federal de São João Del-Rei com ofertas de 96, 74, 70 e 57 cursos, respectivamente.

Já sobre as modalidades de ensino ofertadas pelo sistema UAB destacam-se os cursos na modalidade licenciatura com $53,7 \%$, especialização com $24,5 \%$, aperfeiçoamento com $10 \%$, bacharelado $8,5 \%$ e extensão $3,3 \%$.

Estes dados vêm corroborar com o artigo $1^{\circ}$ do decreto 5.800/06 no qual define ser prioridade do sistema oferecer cursos de licenciatura e de formação inicial e continuada a professores da educação básica, algo evidenciado na variedade de cursos oferecidos na modalidade de licenciatura e especialização.

Já em relação aos cursos oferecidos pelo sistema UAB em Minas Gerais, identifica-se um universo de 48 tipos de cursos, dos quais nota-se uma diversidade de temática e 


\section{EDUCAÇÃO A DISTÂNCIA COMO POLÍTICA DE INCLUSÃO: UM ESTUDO EXPLORATÓRIO NOS \\ POLOS DO SISTEMA UNIVERSIDADE ABERTA DO BRASIL EM MINAS GERAIS \\ DOI: http://dx.doi.org/10.5007/1983-4535.2013v6n2p1}

distribuição, destacando na modalidade licenciatura os cursos de Pedagogia e Matemática com a oferta de 59 e 50 cursos, respectivamente, e bacharelado em Administração Pública com a oferta de 35 cursos. Juntos estes cursos representam quase um terço $(31,4 \%)$ do total dos cursos ofertados pelo sistema UAB em Minas Gerais.

Percebe-se com estes dados a prioridade estabelecida pelo Decreto 5.800/06, em oferecer cursos de licenciatura e de formação inicial e continuada de professores da educação básica, com destaque para cursos de licenciatura em Pedagogia e Matemática, além de oferecer cursos superiores para capacitação de dirigentes, gestores e trabalhadores em educação básica dos Estados, do Distrito Federal e dos Municípios através do bacharelado em Administração Pública. Destaca-se também a variedade de áreas do conhecimento ofertada pelo sistema UAB, ampliando o acesso a educação pública em diversas modalidades de ensino de formação, capacitação e aperfeiçoamento profisssional.

Já em relação ao perfil médio dos municípios mineiros participantes do sistema UAB foi identificado que dois terços $(66,67 \%)$ dos municípios com polos presenciais possuem até 60.000 habitantes, o que de certa forma corrobora com os princípios do sistema UAB que é a de democratizar (potencialmente) o acesso a educação pública superior a regiões cujo acesso local a outras modalidades de ensino apresenta-se limitada, buscando-se nesse sentido, reduzir as desigualdades de oferta de ensino superior entre as diferentes localidades do país (UAB/CAPES; Decreto 5.800/06; Moré et al., 2011; Segenreich, 2009).

Complementando a análise, o município mineiro com menor população identificada foi Pescador com 4.128 habitantes, já a maior população identificada foi Uberlândia com 604.013 habitantes, representando uma média populacional entre todos os polos em funcionamento de 73.756 habitantes, influenciada principalmente pelos limites extremos do universo pesquisado. Como forma de identificar uma medida de tendência central mais realista, calculou-se a mediana da distribuição, representada pelo valor de 30.917 habitantes.

Um ponto de destaque, evidenciado no estudo de caso realizado no polo de Santa Rita de Caldas, permitiu ainda inferir que a democratização de acesso do sistema UAB não se restringe apenas a municípios com polos presenciais estabelecidos, parece haver um alto percentual de alunos matriculados de outras localidades (em torno de 70\%), em especial de município vizinhos, confirmando o papel descentralizador da modalidade UAB em promover o acesso às mais variadas regiões onde estão implantados polos presenciais. 


\section{EDUCAÇÃO A DISTÂNCIA COMO POLÍTICA DE INCLUSÃO: UM ESTUDO EXPLORATÓRIO NOS \\ POLOS DO SISTEMA UNIVERSIDADE ABERTA DO BRASIL EM MINAS GERAIS \\ DOI: http://dx.doi.org/10.5007/1983-4535.2013v6n2p1}

Outro ponto de destaque identificado no estudo de caso refere-se à taxa de evasão de alunos matriculados, em que foram identificados percentuais baixos para os cursos de bacharelado e especialização (em torno de 10\%), e percentuais altos (em torno de $40 \%$ ) para as modalidades de licenciatura gerados, principalmente, pelo grau de adaptação dos alunos aos referidos cursos. Se por um lado as modalidades de bacharelado e especialização apresentam um maior grau comprometimento e adaptação dos alunos, a modalidade de licenciatura apresenta falhas nos processos de adaptação dos alunos com a Educação a Distância, principalmente em cursos que envolvem cálculos como Matemática e Física, o que leva os alunos a se desmotivarem e abandonarem os mesmos. Conforme descrito por Alonso (2010); Moreira \& Kramer (2007) tal fato desperta um desafio às instituições de ensino, sobre novos modelos metodológicos e pedagógicos capazes de motivar e reter alunos.

\subsection{Indicadores socioeconômicos dos municípios participantes:}

Sobre o perfil dos municípios mineiros com polos UAB, percebe-se que o IFDM dos municípios com até 60.000 habitantes corresponde a um IFDM médio de 0,6525 , inferior ao IFDM médio de 0,7789 dos municípios com polos UAB acima de 60.000 habitantes. Assim, como forma de não enviesar a pesquisa foi adotado como critério de análise apenas os municípios com polo UAB de até 60.000 habitantes, sendo esta uma amostra mais homogênea e pertinente, visto a representatividade de $66,67 \%$ (46 municípios) que este conjunto de municípios assume na população total de municípios mineiros com polo UAB.

Assim, ao analisarmos o grupo de municípios com até 60.000 habitantes foi possível identificar uma relação direta entre acesso a educação superior e desenvolvimento municipal, uma vez que, dos dez municípios com maior porcentagem da população economicamente ativa com curso superior, sete destes (Lagoa Santa, Barroso, Bom Despacho, Bambuí, Diamantina, Frutal e Boa Esperança) figuram entre os municípios com maiores IFDM do conjunto pesquisado. De forma análoga, ao analisarmos os dez municípios com menor porcentagem da população economicamente ativa com curso superior, seis destes (Urucuia, Cristália, Buritizeiro, Padre Paraíso, São João da Ponte e Francisco Sá) figuram entre os municípios com piores IFDM do conjunto pesquisado.

Ao analisar este mesmo conjunto de municípios em relação a renda, percebe-se que dos dez municípios com maior porcentagem da população economicamente ativa com curso superior, sete destes (Lagoa Santa, Tiradentes, Bambuí, Bom Despacho, Carneirinho, Frutal e 
Bicas) apresentam os maiores níveis de rendimento nominal mensal percapta dos domicílios. Já os dez municípios com menor porcentagem da população economicamente ativa com curso superior, oito destes (Cristália, Urucuia, Padre Paraíso, São João da Ponte, Buritizeiro, Pedra Azul, Francisco Sá, Durandé) apresentam os piores níveis de rendimento nominal mensal percapta dos domicílios entre os municípios pesquisados.

Corroborando estes dados percebe-se que o rendimento médio mensal dos trabalhadores em municípios de até 60.000 habitantes sem formação superior é de R\$781,11, bem inferior ao rendimento médio mensal dos trabalhadores com formação superior com valor médio de $\mathrm{R} \$ 2.157,50$, representando uma relação direta do grau de instrução com a renda dos trabalhadores. Esses dados demonstram a importância da educação como instrumento de desenvolvimento e combate a desigualdades socioeconômicas (BERTOLIN, 2011; MORAES, 2010; Arieira et al., 2009), o que por meio do sistema UAB pode ser uma importante estratégia de política pública para desenvolvimento local.

Tabela 2 Resumo dos principais valores estatísticos calculados

\begin{tabular}{lccc}
\hline $\begin{array}{c}\text { Variáveis } \\
\text { estatísticas }\end{array}$ & $\begin{array}{c}\text { População dos municípios de } \\
\text { até 60.000 habitantes com } \\
\text { polo UAB }\end{array}$ & $\begin{array}{c}\text { Rendimento nominal mensal } \\
\text { percapta dos domicílios (em } \\
\text { R\$) }\end{array}$ & $\begin{array}{c}\text { IFDM } \\
\mathbf{2 0 1 2}\end{array}$ \\
\hline Média & 24.011 & 620,11 & 0,6525 \\
Maior & 53.468 & $1.362,60$ & 0,8134 \\
Menor & 4.128 & 252,21 & 0,5006 \\
Desvio padrão & 13.429 & 219,49 & 0,0731 \\
\hline
\end{tabular}

Fonte: Elaborado pelos autores

Comparando alguns extremos desta pesquisa exploratória, nota-se que o município de Lagoa Santa possui (em valores percentuais) uma população economicamente ativa com curso superior quase cinco vezes maior que o município de Cristália $(7,40 \%$ contra $1,56 \%$ respectivamente), representando também um rendimento mensal percapta dos domicílios 5,4 vezes maior ( $\mathrm{R} \$ 1.362,60$ contra $\mathrm{R} \$ 252,21)$. Comparando os IFDM destes municípios, percebe-se uma diferença expressiva, com IFDM 0,8134 para Lagoa Santa e IFDM 0,5106 para Cristália, configurando uma relação dos níveis de acesso a educação superior com elevados níveis de IFDM e rendimento mensal percapta, o que em outras palavras, representa uma relação de simetria entre acesso a educação com maior distribuição de renda e desenvolvimento econômico.

Por meio dos resultados apresentados, pode-se verificar a existência de uma relação positiva entre nível educacional e desenvolvimento econômico, destacando que a inclusão 
social promovida pelo sistema UAB pode contribuir para o desenvolvimento local (BERTOLIN, 2011; MORAES, 2010; Nascimento \& Trompieri Filho, 2002; MACHADO, 2001), principalmente em municípios de até 60.000 habitantes com índices de desenvolvimentos baixos, conforme apresentado neste estudo.

Corroborando estes dados, evidenciou-se no estudo de caso realizado que a Educação a Distância tem promovido desenvolvimento socioeconômico local, pois através de relatos dos gestores, identificou-se o surgimento de novas oportunidades de emprego e renda aos alunos do sistema. Os mesmos relataram haver claras evidências do aumento no número de alunos provenientes de cursos de licenciatura aprovados em concursos públicos. Relatam ainda indícios de acréscimo salarial a servidores públicos com a titulação adquirida em cursos de bacharelado, licenciatura e especialização na modalidade a distância, além do surgimento de novas vagas de emprego e melhorias na renda dos alunos participantes.

Assim, percebe-se com este estudo que o sistema UAB mostra-se como um importante instrumento de inclusão social, evidenciando que a Educação a Distância pode apresentar diversos benefícios aos municípios participantes por meio de mecanismos de inclusão capazes de gerar maior distribuição de renda e desenvolvimento socioeconômico local.

\section{CONSIDERAÇÕES FINAIS}

A Educação a Distância tem sido uma importante via de descentralização e expansão da oferta de ensino público superior no país. Neste cenário, percebe-se que o sistema UAB tem se destacado como uma importante política pública de acesso a educação em diversas regiões do país, por meio da articulação de instituições públicas e municípios com a oferta de cursos a diversos setores estratégicos da política nacional de educação.

Nesta perspectiva, este estudo tentou estabelecer uma análise sobre os possíveis impactos socioeconômicos que o sistema UAB pode promover em municípios mineiros participantes do sistema com até 60.000 habitantes. Assim, buscou-se por meio do cruzamento de índices econômicos disponíveis em bases de dados de órgãos federais e estaduais, triangular as informações coletadas com um estudo de caso realizado no município de Santa Rita de Caldas/MG, em que foi possível identificar evidências de forte relação entre níveis de acesso a educação e desenvolvimento socioeconômico, estando os municípios com maiores índices de acesso ao ensino superior entre os municípios com maior distribuição de renda e desenvolvimento municipal classificado pelo IFDM. 


\section{EDUCAÇÃO A DISTÂNCIA COMO POLÍTICA DE INCLUSÃO: UM ESTUDO EXPLORATÓRIO NOS \\ POLOS DO SISTEMA UNIVERSIDADE ABERTA DO BRASIL EM MINAS GERAIS \\ DOI: http://dx.doi.org/10.5007/1983-4535.2013v6n2p1}

Cabe ressaltar que este artigo possui algumas limitações por ser um esforço inicial, baseado apenas em informações documentais exploratórias - descritivas e na análise da entrevista em profundidade realizada com os gestores responsáveis pela implantação e coordenação de apenas um polo presencial (Santa Rita de Caldas) o que pode apresentar vieses sobre a realidade entre outros polos do Estado.

Outra limitação identificada se refere ao perfil médio dos municípios apresentado, pois apesar da tentativa de homogeneizar um grupo com características similares (até 60.000 habitantes) o mesmo ainda apresenta grandes variações populacionais, de renda, acesso a educação e desenvolvimento socioeconômico. Para maior confiabilidade dos resultados, sugere-se classificar municípios com características ainda mais semelhantes, a fim de buscar maior aproximação das hipóteses levantadas em nossa pesquisa.

Embora este estudo apresente uma relação de simetria entre acesso à educação superior e desenvolvimento socioeconômico, não se pode afirmar que o desenvolvimento local é dependente apenas de acesso a educação superior, assumindo uma relação econômica de ceteris paribus, outros indicadores e fatores também devem ser analisados para maximização dos níveis de desenvolvimento municipal.

Ademais, novas pesquisas teóricas e empíricas tornam-se necessárias para ampliar o debate aqui iniciado, com objetivo de impulsionar gestores municipais a demandarem novos polos de apoio presencial e avaliar as possíveis repercussões que a oferta pública de cursos superiores pode gerar no desenvolvimento econômico e social de cada município.

\section{REFERÊNCIAS}

ALLEN, I. E.; SEAMAN, J. Class differences: On-line education in the United States. Needham, MA: Sloan Consortium, 2010.

ALONSO, K. M. A expansão do ensino superior no Brasil e a EaD: Dinâmicas e lugares. Educ. Soc., Campinas, v. 31, n. 113, p. 1319-1335, out.-dez. 2010.

APPOLINÁRIO, F. Dicionário de metodologia científica: um guia para a produção do conhecimento científico. São Paulo, Atlas, 2009.

ARBAUGH, J. B; BENBUNAN-FICH, R. An Investigation of Epistemological and Social Dimensions of Teaching in Online Learning Environments. Academy of Management Learning \& Education, 2006, v. 5, n. 4, 435-447. 
ARIEIRA, J. O.; DIAS-ARIEIRA, C. R.; FUSCO, J. P. A.; SACOMANO, J. B.; BETTEGA, M. O. P.. Avaliação do aprendizado via Educação a Distância: a visão dos discentes. Ensaio: Avaliação e Políticas Públicas em Educação, v. 17, n.63, p. 1-20, Rio de Janeiro, 2009.

BERTOLIN, J. C. G. Uma proposta de indicadores de desempenho para a educação superior brasileira. Est. Aval. Educ., São Paulo, v. 22, n. 50, p. 471-490, set./dez. 2011.

BRASIL. Decreto 5.622 de 19 de Dezembro de 2005. Regulamenta o art. 80 da Lei no 9.394 , de 20 de dezembro de 1996, que estabelece as diretrizes e bases da educação nacional. Diário Oficial da União, Brasília, DF, 20 dez. 2010.

Decreto 5.800 de 08 de Junho de 2006. Dispõe sobre o Sistema Universidade Aberta do Brasil - UAB. Diário Oficial da União, Brasília, DF, 09 jun. 2006.

Decreto 6.303 de 12 de Dezembro de 2007. Altera dispositivos dos Decretos $\mathrm{n}^{\mathrm{os}}$ 5.622, de 19 de dezembro de 2005, que estabelece as diretrizes e bases da educação nacional, e 5.773, de 9 de maio de 2006, que dispõe sobre o exercício das funções de regulação, supervisão e avaliação de instituições de educação superior e cursos superiores de graduação e seqüenciais no sistema federal de ensino. Diário Oficial da União, Brasília, DF, 2007.

COSTA, M. L. F. História e políticas públicas para o ensino superior à distância no Brasil: o programa universidade aberta do brasil em questão. Revista HISTEDBR On-Line, v. 12, n. 45, 2012.

GATTI, B. A. Análise das políticas públicas para formação continuada no Brasil, na última década. Revista Brasileira de Educação 13(37): 57-70, 2008.

GIL, A. C. Como elaborar projetos de pesquisa. 4 ed. São Paulo: Atlas, 2002.

MACHADO, N. J. A Universidade e a organização do conhecimento: a rede, o tácito, a dádiva. Estudos avançados,vol.15, no.42, 2001.

MAIA, M. C.; MEIRELLES, F. S. Educação a Distância: O caso Open University. RAEeletrônica, v.1, n.1, jan-jun/2002.

MATIAS-PEREIRA, J. "Políticas públicas de educação no Brasil: a utilização da EAD como instrumento de inclusão social." Journal of Technology Management \& Innovation, 2008.

MEC/INEP - Instituto Nacional de Estudos e Pesquisas Educacionais Anísio Teixeira. Censo da educação superior: 2010 - resumo técnico. Brasília: Instituto Nacional de Estudos e Pesquisas Educacionais Anísio Teixeira, 2012. 85 p.

MINISTÉRIO DE ESTADO DA EDUCAÇÃO. Portaria 1.369, de 7 de Dezembro de 2010. Dispõe sobre Credenciar as Instituições Públicas de Educação Superior,vinculadas ao Sistema Universidade Aberta do Brasil, para a oferta de cursos superiores na modalidade a distância, pelo prazo de 5 (cinco) anos; e credenciar os polos de apoio presencial para a modalidade de Educação a Distância. Diário Oficial da União, Brasília, DF, 8 dez. 2010. 
MOHAMED, F. A.; HASSAN, A. M; SPENCER, B. Conceptualization and measurement of perceived risk of online education. Academy of Educational Leadership Journal, 2011. MORAES, R. C. C. Educação a Distância e efeitos em cadeia. Cadernos de Pesquisa, v.40, n.140, p. 547-559, maio/ago. 2010.

MORÉ, et. al. Educação a Distância e formação docente: o sistema Universidade Aberta do Brasil como forma de ampliar o acesso à educação superior. Revista Gestão Universitária na América Latina: 89-109, 2011.

MOREIRA, A. F. B.; KRAMER, S. Contemporaneidade, educação e tecnologia. Educação \& Sociedade, Campinas, v. 28, n. 100, 2007.

NASCIMENTO, R. B.; TROMPIERI FILHO, N. Correio eletrônico como recurso didático no ensino superior: o caso da Universidade Federal do Ceará. Ciência da Informação, Brasília, DF, v. 31, n. 2, 2002.

NOGUEIRA, L. L. 1996. Educação a Distância. Comunicação e Educação. São Paulo, Moderna, Ano II, (5): 34-9, jan./abr., 1996.

OLIVEIRA, M. M. Como fazer pesquisa qualitativa. Petrópolis, Vozes, 2007.

PARIETTI, I.S.C.; TURI, D. M. Assessment of the online instructor. Academy of Educational Leadership Journal, V.15, Special Issue, 2011.

PEREIRA, J. M. Políticas públicas de educação no Brasil: a utilização da EAD como instrumento de inclusão social. Journal of Technology Management \& Innovation, 2008.

REDPATH, L. Confronting the Bias Against On-Line Learning in Management Education. Academy of Management Learning \& Education, v. 11, n.1, 125-140, 2012.

SEGENREICH, S. "Educação superior a distância: políticas públicas e realidades institucionais." 26 ${ }^{\mathbf{a}}$ Reunião Anual da ANPEd: 187-188, 2003.

SEGENREICH, S. C. D. ProUni e UAB como estratégias de EAD na expansão do ensino superior. Pró-Posições/Universidade Estadual de Campinas: 205-222, 2009.

UAB/CAPES. Portal Universidade Aberta do Brasil. Disponível em:

$<$ http://uab.capes.gov.br> acesso em 31 de Janeiro de 2012.

WEIDLE, D.; KICH, J. I. D. F.; PEREIRA, M. F. Projeto UAB: uma análise estrutural dos polos de apoio presencial do curso de Administração da UFSC. Revista Gestão

Universitária na América Latina, v. 4, n. 4, p. 94-114, 2011. 